\title{
Antimicrobial Constituents from Leaves of Dolichandrone spathacea and Their Relevance to Traditional Use
}

\section{() (1) $\odot \Theta$}

\author{
Authors \\ Phuc-Dam Nguyen ${ }^{1}$, Amin Abedini ${ }^{1,2}$, Sophie C. Gangloff ${ }^{2}$, Catherine Lavaud1
}

Affiliations

1 Institut de Chimie Moléculaire de Reims, CNRS UMR 7312, Reims, France

2 Laboratoire de Microbiologie, EA 4691, UFR de Pharmacie, Reims, France

\section{Keywords}

Dolichandrone spathacea, Bignoniaceae, iridoid glycosides, triterpenoid saponins, antibacterial activity

$\begin{array}{ll}\text { received } & 14.07 .2017 \\ \text { revised } & 14.11 .2017 \\ \text { accepted } & 11.12 .2017\end{array}$

Bibliography

DOI https://doi.org/10.1055/s-0043-125339

Planta Med Int Open 2018; 5: e14-e23

(c) Georg Thieme Verlag KG Stuttgart · New York ISSN 2509-9264

\section{Correspondence}

Prof. Catherine Lavaud

Institut de Chimie Moléculaire de Reims (ICMR)

CNRS UMR 7312

BP 1039

51687 Reims Cedex 2

France

Tel.: + 33/3/26913139

catherine.lavaud@univ-reims.fr Supporting information is available online at
http://www.thieme-connect.de/products

\section{ABSTRACT}

Five new compounds, three iridoid glycosides (1-3) and two triterpenoid saponins $(\mathbf{4}, \mathbf{5})$, along with thirty-two known compounds were isolated from the methanolic extract of the leaves of Dolichandrone spathacea. This traditional medicinal plant is widely used in Asia and India as antiseptic, for bronchitis and thrush treatment, and the methanolic extract has been shown to possess antibacterial activity against methicillin-resistant Staphylococcus aureus. The new iridoids were esterified derivatives of 6-ajugol and 6-catalpol, and the new saponins were glucosides of two polyhydroxy triterpenes with ursan skeleton. Their structures were elucidated by spectroscopic methods, including 1D and 2D NMR experiments and HR-ESI-MS analysis, and from comparison with the literature. This study aimed at investigating extracts and isolated compounds for their antimicrobial activities against bacterial and yeast strains, in order to validate the uses of the plant in folk medicine. The 6-O-esterified iridoids had weaker antibacterial activity; verbascoside and p-methoxycinnamic acid, the major compounds of the methanol extract, possessed strong antibacterial activity, which could account for the traditional antiseptic and anti-infectious uses of the leaves of $D$. spathacea.

\section{Introduction}

Dolichandrone spathacea (L.f.) Seem. (Bignoniaceae) also known as mangrove trumpet tree, is a common tree growing wild in river banks and mangroves of the Asia-Pacific area [1]. The leaves are used as an antitumor, antiseptic, and to treat oral thrush (as mouthwash), nervous diseases and flatulence in many countries of Southeast Asia $[1,2]$. The juice of the leaves is used orally against bronchitis in India [3]. In Vietnam, this plant is part of a traditional medication (Tiêu Phong Nhuân Gan), used against hepatic disorders, skin diseases, allergies, and as detoxifier, anti-inflammatory and laxative. Several biological activities of leaves extracts were measured showing for example, that the polar extracts possessed a high antiradical activity [2] and that the aqueous methanol extract exhibited an inhibitory effect against rat intestinal maltase [4]. Literature also reports that a methanol extract from the leaves exhibited a strong growth inhibition of six strains of methicillin-resistant Staphylococcus aureus (MRSA) [5]. The same article demonstrated, in a preliminary approach, the detection of flavonoids, saponins, triterpenes, and tannins in the leaves but without any structural characterization [5]. In the present paper, we report the isolation and characterization of 
phytochemical constituents from leaves of $D$. spathacea, and the evaluation of antimicrobial activities of extracts and isolated compounds against different microorganisms.

\section{Results and Discussion}

The leaves of $D$. spathacea were extracted by successive percolations with petroleum ether, chloroform, ethyl acetate, methanol, and $80 \%$ aqueous methanol. The methanolic extract was purified by using a combination of liquid chromatographic techniques to yield 37 compounds. Among these, five were new compounds: three iridoid glucosides (1-3) and two triterpenoid saponins (4 and 5) ( Fig. 1). The 32 known isolated compounds were: 6-O-p-Ecoumaroyl-ajugol [6], 6-O-E-caffeoyl-ajugol and 6-O-E-isoferuloylajugol [7], nemorososide [8], 6-O-(E)-cinnamoyl-catalpol [9], specioside [10], 6-(E)-p-methoxycinnamoyl-catalpol [11], a mixture of (E)- and (Z)-6-p-methoxycinnamoyl-catalpol [12], verminoside and minecoside [13], nemoroside and 6"'(Z)-nemoroside [14], ixoside [15], arjunglucoside I [16], decaffeoylacteoside [17], verbascoside (or acteoside) [18], isoverbascoside (or isoacteoside) [19], luteolin, luteolin-7-O- $\beta$-D-glucopyranoside, luteolin-7-O- $\beta$-Dglucuronide and luteolin-7-O-rutinoside [20-23], (2E,6E)-8-hydroxy-2,6-dimethyl-2,6-octadienoic acid [24], (2E,6Z)-8-hydroxy-2,6-dimethyl-2,6-octadienoic acid [25], 6 R- and 6S-(2E)8 -hydroxy-2,6-dimethyl-2-octenoic acid in mixture [26, 27], p-hydroxybenzoic acid [28], vanillic acid [29], p-hydroxycinnamic and p-methoxycinnamic acids [30], isoferulic acid [31], and 6S,9Sroseoside [32,33].

The new compounds (1-5) possessed the same sugar residue in their structures ( $\triangleright$ Table $\mathbf{1}$ and $\mathbf{2}$ ), which was determined as D-glucose after acid hydrolysis and chiral HPLC analysis. NMR showed that it was in the $\beta$-D-pyranosyl configuration.

The ${ }^{1} \mathrm{H}-\mathrm{NMR}$ data ( $>$ Table $\mathbf{1}$ ) of $\mathbf{1}$ and $\mathbf{2}$ revealed the characteristic signals of an ajugol part [6] with an acetal proton at $\delta_{H} 5.53$, two cis olefinic protons at $\delta_{H} 6.24$ and 5.00, one methyl singlet at $\delta_{H} 1.41$, and a deshielded hydroxymethine proton at $\delta_{H} 4.96$. The ${ }^{13} \mathrm{C}-\mathrm{NMR}$ (DEPT and HSQC) data confirmed the presence of the ajugol moiety ( Table 1) [6], and the relative stereochemistry was confirmed by observation of ROE effects between $\mathrm{H}-5 \beta / \mathrm{H}-9 \beta$, $\mathrm{H}-1 \alpha / \mathrm{H}-10 \alpha, \mathrm{H}-10 \alpha / \mathrm{H}-7 \alpha, \mathrm{H}-7 \alpha / \mathrm{H}-6 \alpha$, and the absence of an ROE effect between $\mathrm{H}-5 \beta / \mathrm{H}-1 \alpha$ and $\mathrm{H}-6 \alpha / \mathrm{H}-9 \beta$.

The molecular formula of 1 was determined to be $\mathrm{C}_{25} \mathrm{H}_{32} \mathrm{O}_{11}$ by HR-ESI-MS analysis [molecular ion at $\mathrm{m} / \mathrm{z} 531.1848$ [M + Na] ${ }^{+}$ (calcd. for $\mathrm{C}_{25} \mathrm{H}_{32} \mathrm{O}_{11} \mathrm{Na}$, 531.1842)]. By subtracting the ajugol part, there remained a $\mathrm{C}_{10} \mathrm{H}_{24} \mathrm{O}_{9}$ (161 uma) residue. It was assigned to a p-O-methoxycinnamoyl group by NMR: AA'BB' system of four aromatic protons at $\delta_{\mathrm{H}} 7.56(2 \mathrm{H})$ and $6.97(2 \mathrm{H})$, one E-double bond at $\delta_{H} 7.68$ and $6.43(\mathrm{~J}=16.0 \mathrm{~Hz})$, and one methoxy group at $\delta_{\mathrm{H}} 3.85$. The ester carbonyl carbon at $\delta_{C} 167.4$ (C-9') showed an HMBC correlation with $\mathrm{H}-6$ of ajugol moiety and therefore, compound $\mathbf{1}$ was determined as 6-O-(p-methoxy-E-cinnamoyl)-ajugol.

Iridoid glucoside (2) showed a molecular ion peak $[\mathrm{M}+\mathrm{Na}]^{+}$at $\mathrm{m} / \mathrm{z} 539.2462$ (calcd. for $\mathrm{C}_{25} \mathrm{H}_{40} \mathrm{O}_{11} \mathrm{Na}, 539.2468$ ) in agreement with a $\mathrm{C}_{25} \mathrm{H}_{40} \mathrm{O}_{11}$ formula. Its ${ }^{1} \mathrm{H}$ - and ${ }^{13} \mathrm{C}$-NMR spectra ( Table 1) were similar to those of $\mathbf{1}$ with characteristic signals for a 6 -esterified derivative of ajugol. The ${ }^{13} \mathrm{C}-\mathrm{NMR}$ and DEPT spectra of $\mathbf{2}$ exhibited ten carbons for a monoterpenic acid elucidated as 8-hy- droxy-2,6-dimethyl-2-octenoic acid which was isolated as pure known compound (see below) [26, 27] ( Table 1). An E-configuration could be assigned to the trisubstituted double bond according to the shielding of $\mathrm{CH}_{3}-9$ "' at $\delta_{\mathrm{C}} 12.4$ in comparison with $\delta_{\mathrm{C}}$ 22-25 for Z-configuration [34]. To determine the absolute configuration of the $\mathrm{CH}-6$ ", we carried out the alkaline hydrolysis of $\mathbf{2}$ and then the monoterpenic acid was purified by semi-preparative HPLC [18]. The positive sign of the optical rotation of the isolated acid indicated that it was $6 \mathrm{R}$-(2E)-8-hydroxy-2,6-dimethyl-2-octenoic acid. The absence of any supplementary peak in the ${ }^{13} \mathrm{C}$ as well as ${ }^{1} \mathrm{H}$ NMR spectra demonstrated that $\mathbf{2}$ was diastereoisomerically pure despite the fact that the optical rotation value of the acid $\left([\alpha]_{D}=+3.7\right)$ was lower than those found in the literature $[26,27]$. This discrepancy is most probably due to difficulties in measuring rotations on tiny amounts of material. We concluded that $\mathbf{2}$ was 6"R-O-(2E) -8-hydroxy-2,6-dimethyl-2-octenoyl-ajugol.

The HR-ESI-MS analysis of the third new iridoid glucoside (3) revealed a molecular formula of $\mathrm{C}_{25} \mathrm{H}_{38} \mathrm{O}_{12}$ with the molecular ion at $\mathrm{m} / \mathrm{z} 553.2256[\mathrm{M}+\mathrm{Na}]^{+}$(calcd. for $\mathrm{C}_{25} \mathrm{H}_{38} \mathrm{O}_{12} \mathrm{Na}, 553.2261$ ). The comparison of ${ }^{1} \mathrm{H}$ - and ${ }^{13} \mathrm{C}$-NMR spectral data ( $\triangleright$ Table 1 ) of compounds $\mathbf{2}$ and $\mathbf{3}$ showed great similarities for the ester monoterpene parts. The iridoid skeleton of $\mathbf{3}$ was identified as catalpol [14] with only one deshielded proton $\mathrm{H}-7$ at $\delta_{\mathrm{H}} 3.70$ (brs) and two oxygenated carbons for $\mathrm{CH}_{2} \mathrm{OH}-10$ at $\delta_{\mathrm{C}} 61.3$ and $-\mathrm{CHO}-7$ at $\delta_{\mathrm{C}} 60.2$ [35]. The relative stereochemistry of the six asymmetric centers was confirmed by analysis of ROE effects. The stereochemistry of the carbon C-6" of the monoterpenic acid was determined by the same method as that employed for hydrolysis of $\mathbf{2}$. The same optical rotation $\left([\alpha]_{D}=+3.7\right)$ was measured and compound 3 was identified as 6"'R-O-(2E)-8-hydroxy-2,6-dimethyl-2-octenoyl)-catalpol.

The positive HR-ESI-MS of saponin (4) gave a molecular ion peak $[\mathrm{M}+\mathrm{Na}]^{+}$at $\mathrm{m} / \mathrm{z} 673.3934$ (calcd. for $\mathrm{C}_{36} \mathrm{H}_{58} \mathrm{O}_{10} \mathrm{Na} 673.3928$ ) corresponding to a molecular formula $\mathrm{C}_{36} \mathrm{H}_{58} \mathrm{O}_{10}$. The presence of 36 carbons was observed in the ${ }^{13} \mathrm{C}$-NMR spectrum including 6 carbons for a $\beta$-D-glucopyranose and 30 carbons for a $\Delta^{12}$ ursene skeleton with $\delta_{\mathrm{C}} 130.0(\mathrm{CH}-12)$ and 138.9 (C-13; - Table 2). The glucose unit was linked to the triterpene moiety at position $\mathrm{C}-28$ since an $\mathrm{HMBC}$ correlation was observed between the anomeric proton $\mathrm{H}-1$ ' and the carbonyl C-28 at $\delta_{\mathrm{C}} 178.5$ [36]. The aglycone was determined to be triterpene uncaric acid (or $3 \beta, 6 \beta, 19 \alpha$-trihydroxyurs12-en-28-oic acid) [37]. The $3 \beta-\mathrm{OH}$ configuration was confirmed by the large coupling constant ${ }^{3} \mathrm{~J}_{\mathrm{H}-3 \mathrm{ax} / \mathrm{H}-2 \mathrm{ax}}=11.7 \mathrm{~Hz}$ suitable with an $(\alpha)$ axial $H-3$, the hydroxyl group being in equatorial position ( $\beta$ ). The ROE effects observed between $\mathrm{H}-6$ and $\mathrm{H}-5 \alpha$, and between $\mathrm{H}-6$ and $\mathrm{H}-23 \alpha$ indicated a $6 \beta-\mathrm{OH}$ configuration. The third hydroxyl group was localized in axial position $(19 \alpha-\mathrm{OH})$ due to the observation of ROE between the axial proton $\mathrm{H}-18 \beta$ and the equatorial methyl $\mathrm{CH}_{3}-29 \beta$. Thus, compound 4 was identified as $28-O-\beta-D-$ glucopyranosyl-3 $\beta, 6 \beta, 19 \alpha$-trihydroxyurs-12-en-28-oic acid, named 28-O- $\beta$-D-glucopyranosyl uncaric acid.

The positive HR-ESI-MS of saponin (5) displayed a molecular ion peak $[\mathrm{M}+\mathrm{Na}]^{+}$at m/z 689.3869 (calcd. for $\mathrm{C}_{36} \mathrm{H}_{58} \mathrm{O}_{1} \mathrm{Na}$, 689.3877) consistent with the molecular formula $\mathrm{C}_{36} \mathrm{H}_{58} \mathrm{O}_{11}$, therefore a hydroxylated derivative of saponin 4. Comparison of the NMR spectral data of $\mathbf{4}$ and $\mathbf{5}$ revealed significant similarities ( $>$ Table $\mathbf{2}$ ); the difference was the existence of only six methyl groups and an additional hydroxyl group located at position C-23 or C-24 according 


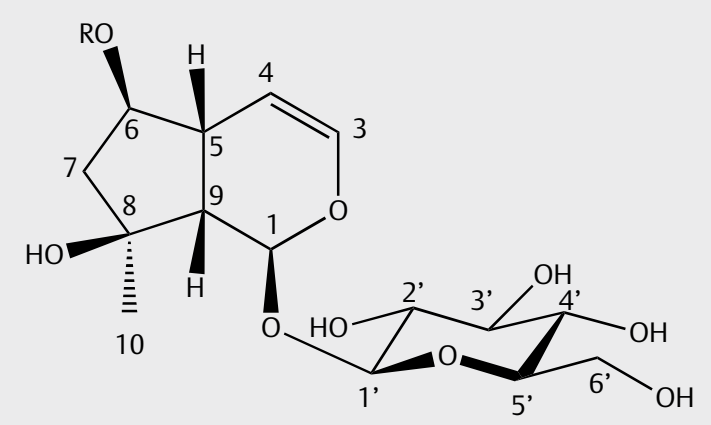

$1 \mathrm{R}=$

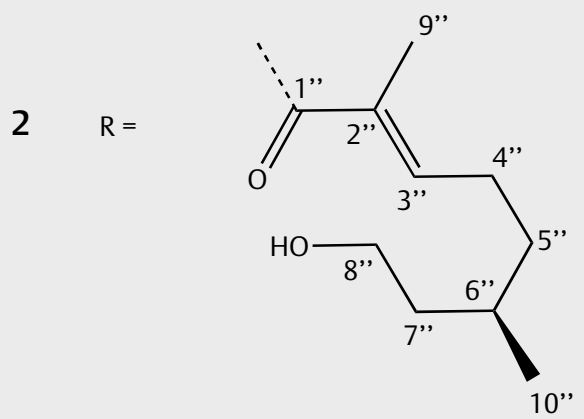

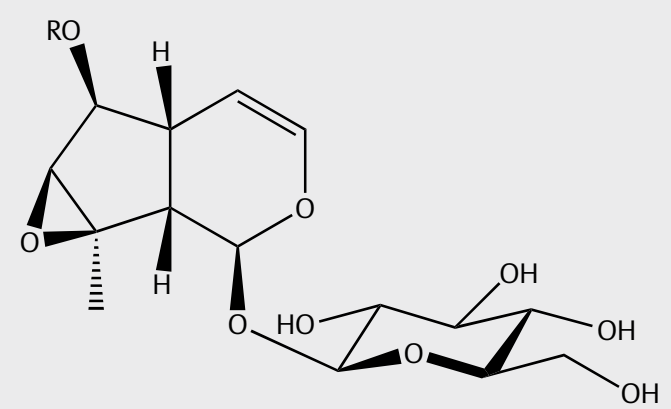

$3 \quad \mathrm{R}=$

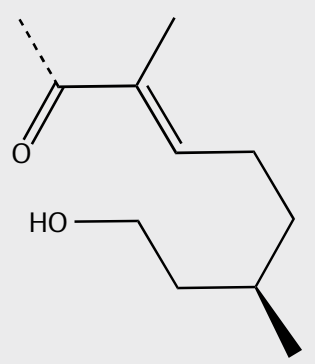

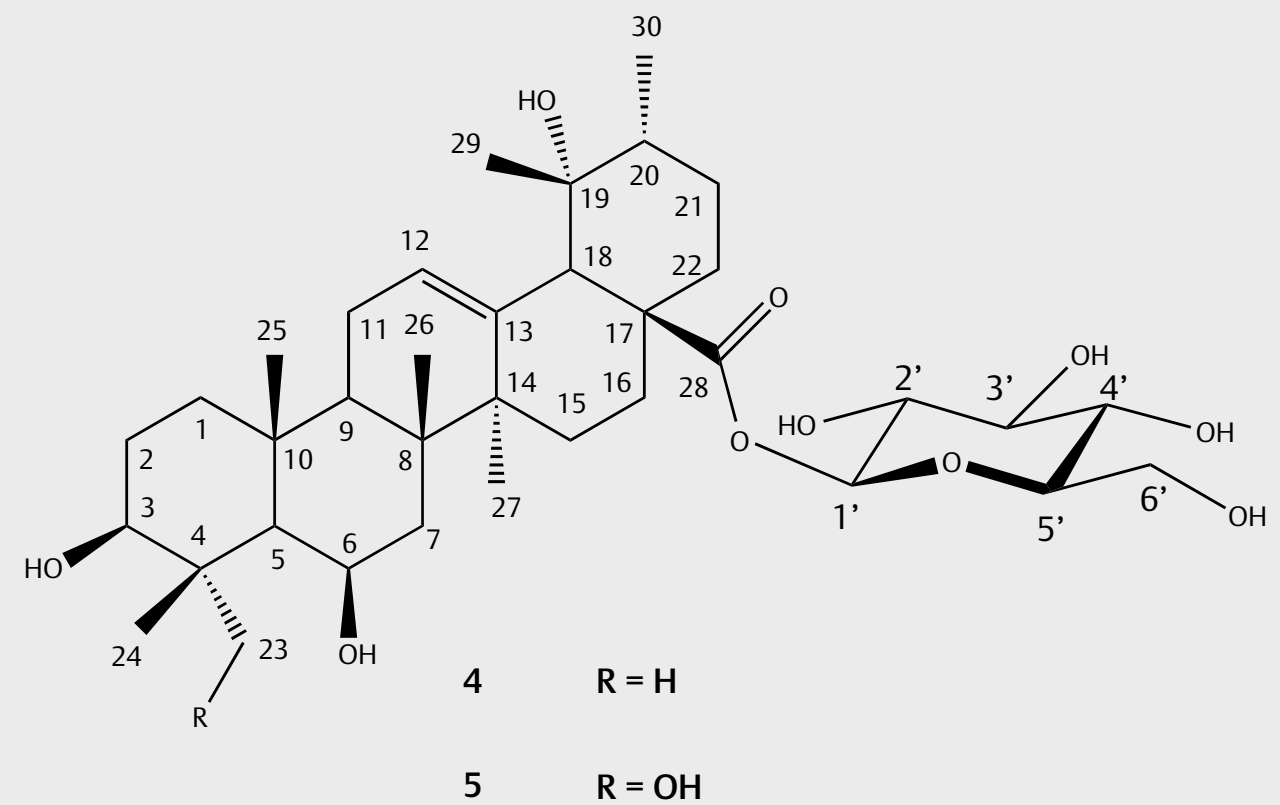

- Fig. 1 Chemical structures of iridoids $(1,2,3)$ and saponins $(4,5)$.

to $\mathrm{HMBC}$ correlations between the supplementary protons $\mathrm{CH}_{2}$ $\mathrm{OH}$ and carbons $\mathrm{C}-3, \mathrm{C}-4$, and $\mathrm{C}-5$. The ROE effects observed between $\mathrm{H}-6 \alpha / \mathrm{H}-5 \alpha$, and between $\mathrm{H}-6 \alpha$ and $\mathrm{CH}_{2}-\mathrm{OH}$ confirmed the $\alpha$-equatorial position of $23-\mathrm{CH}_{2}-\mathrm{OH}$. The expected effects due to 24-hydroxylation were well observed on C-23 $(\Delta \alpha=+38.4)$, C-4 $(\Delta \beta=+3.5), C-24(\Delta \gamma=-3.5), C-5(\Delta \gamma=-6.7)$, and C-3 $(\Delta y=-6.3$; - Table 2). Thus, the aglycone of 5 was $3 \beta, 6 \beta, 19 \alpha, 23$-tetrahydroxyurs-12-en-28-oic acid [38], and saponin $\mathbf{5}$ was identified as 
- Table $1{ }^{1} \mathrm{H}$ - and ${ }^{13} \mathrm{C}-\mathrm{NMR}$ spectroscopic data $\left(\mathrm{CD}_{3} \mathrm{OD}\right)$ of iridoids (1), (2) and (3).

\begin{tabular}{|c|c|c|c|c|c|c|}
\hline & \multicolumn{2}{|l|}{ (1) } & \multicolumn{2}{|l|}{$(2)$} & \multicolumn{2}{|l|}{ (3) } \\
\hline & $\delta_{\mathrm{H}}(\mathrm{J}$ in $\mathrm{Hz})$ & $\delta_{\mathrm{C}}$ & $\delta_{\mathrm{H}}(\mathrm{J}$ in $\mathrm{Hz})$ & $\delta_{\mathrm{C}}$ & $\delta_{\mathrm{H}}(\mathrm{J}$ in $\mathrm{Hz})$ & $\delta_{\mathrm{C}}$ \\
\hline 1 & $5.53, \mathrm{~d}(2.5)$ & 92.0 & $5.56, d(2.4)$ & 93.4 & $5.18, d(9.6)$ & 95.1 \\
\hline 3 & $6.24, \mathrm{dd}(6.3,2.2)$ & 139.7 & $6.23, \mathrm{dd}(6.3,2.2)$ & 141.1 & $6.39, \mathrm{~d}(6.0)$ & 142.4 \\
\hline 4 & $5.00, \mathrm{dd}(6.3,2.6)$ & 103.2 & $4.97, \mathrm{dd}(6.3,2.7)$ & 104.6 & 4.98, dd $(5.6,4.1)$ & 102.9 \\
\hline 5 & $2.95, \mathrm{dd}(9.1,2.3)$ & 38.0 & $2.90, \mathrm{dq}(9.2,2.2)$ & 39.3 & 2.61-2.56, m & 36.7 \\
\hline 6 & 4.96, ddd $(6.5,4.1,2.7)$ & 78.9 & 4.89, m & 80.5 & $4.98, d(7.7)$ & 81.6 \\
\hline 7 & $\begin{array}{l}2.02, \mathrm{dd}(14.2,4.0) \beta \\
2.27, \mathrm{dd}(14.2,6.4) \alpha\end{array}$ & 46.5 & $\begin{array}{l}2.23, \mathrm{dd}(14.3,6.5) \alpha \\
1.98, \mathrm{dd}(14.3,4.0) \beta\end{array}$ & 47.8 & 3.70 , brs & 60.2 \\
\hline 8 & & 77.7 & & 79.0 & & 66.8 \\
\hline 9 & $2.60, \mathrm{dd}(9.3,2.3)$ & 50.2 & $2.59, \mathrm{dd}(9.2,2.0)$ & 51.6 & 2.63, dd $(9.3,7.9)$ & 43.2 \\
\hline 10 & $1.41, \mathrm{~s}$ & 24.7 & $1.39, \mathrm{~s}$ & 26.1 & $\begin{array}{l}4.18, d(13.2) \\
3.85, d(13.1)\end{array}$ & 61.3 \\
\hline \multicolumn{7}{|c|}{$\beta$-D-glucopyranose $(\mathrm{C}-1)$} \\
\hline $1^{\prime}$ & 4.69, d (8.0) & 98.0 & $4.68, d(7.9)$ & 99.4 & $4.81, \mathrm{~d}(7.9)$ & 99.7 \\
\hline $2^{\prime}$ & $3.22, \mathrm{dd}(9.2,7.9)$ & 73.4 & $3.22, \mathrm{dd}(9.2,8.1)$ & 74.8 & $3.30, \mathrm{dd}(8.8,8.3)$ & 74.9 \\
\hline $3^{\prime}$ & $3.39, \mathrm{dd}(9.2,8.7)$ & 76.6 & $3.59, \mathrm{t}(8.9)$ & 78.0 & $3.43, \mathrm{t}(9.0)$ & 77.7 \\
\hline $4^{\prime}$ & $3.31, \mathrm{dd}(9.2,8.6)$ & 71.8 & $3.29, \mathrm{dd}(9.7,8.5)$ & 71.7 & $3.28, \mathrm{t}(9.3)$ & 71.8 \\
\hline $5^{\prime}$ & $3.32-3.35, \mathrm{~m}$ & 76.8 & 3.32-3.35, m & 78.2 & 3.35, ddd $(9.4,6.3,1.5)$ & 78.7 \\
\hline $6^{\prime}$ & $\begin{array}{l}\text { 3.68, dd }(12.0,6.0) \\
3.92, \mathrm{dd}(12.0,2.2)\end{array}$ & 61.5 & $\begin{array}{l}\text { 3.68, dd }(12.0,5.9) \\
3.92, \mathrm{dd}(12.0,3.1)\end{array}$ & 62.9 & $\begin{array}{c}\text { 3.67, dd }(12.2,6.1) \\
3.95, \text { brd }(11.9)\end{array}$ & 62.9 \\
\hline \multicolumn{7}{|c|}{ 6-Acyl ester } \\
\hline $1 "$ & & 167.4 & & 169.5 & & 169.5 \\
\hline 2" & $6.43, d(16.0)$ & 115.0 & & 128.8 & & 128.3 \\
\hline 3" & $7.68, \mathrm{~d}(16.0)$ & 144.8 & $6.83, \operatorname{td}(7.5,1.3)$ & 144.3 & $6.88, \mathrm{t}(7.3)$ & 145.0 \\
\hline 4" & & 127.0 & 2.20-2.32, m & 27.2 & $2.22-2.35, \mathrm{~m}$ & 27.3 \\
\hline $5 "$ & $7.56, d(8.6)$ & 129.6 & $\begin{array}{l}1.47-1.54, \mathrm{~m} \\
1.29-1.34, \mathrm{~m} \\
\end{array}$ & 36.9 & $\begin{array}{l}1.49-1.56, \mathrm{~m} \\
1.30-1.37, \mathrm{~m} \\
\end{array}$ & 36.9 \\
\hline 6" & $6.97, \mathrm{~d}(8.7)$ & 114.0 & 1.64-1.66, m & 30.5 & $1.60-1.67, \mathrm{~m}$ & 30.5 \\
\hline 7" & & 161.9 & $\begin{array}{l}1.59-1.64, \mathrm{~m} \\
1.35-1.40, \mathrm{~m}\end{array}$ & 40.6 & $\begin{array}{c}1.60-1.65, \mathrm{~m} \\
1.41 .37-1.43, \mathrm{~m}\end{array}$ & 40.6 \\
\hline $8 "$ & $7.56, d(8.6)$ & 114.0 & $\begin{array}{c}\text { 3.62-3.67, m } \\
3.58-3.3 .62, \mathrm{~m}\end{array}$ & 60.9 & 3.58-3.66, m & 60.9 \\
\hline $9 "$ & $6.97, d(8.7)$ & 129.6 & $1.85, \mathrm{~s}$ & 12.4 & $1.89, \mathrm{~s}$ & 12.5 \\
\hline $10 "$ & & & $0.97, \mathrm{~d}(6.5)$ & 19.8 & $0.97, \mathrm{~d}(6.4)$ & 19.8 \\
\hline $\mathrm{OCH}_{3}$ & $3.85(\mathrm{~s})$ & 54.5 & & & & \\
\hline
\end{tabular}

28-O- $\beta$-D-glucopyranosyl-3 $\beta, 6 \beta, 19 \alpha 23$-tetrahydroxyurs-12-en28-oic acid, or 28-O- $\beta$-D-glucopyranosyl-23-hydroxy-uncaric acid.

MIC were determined for the five extracts prepared from the leaves of $D$. spathacea against $8 \mathrm{Gram}$-positive bacterial strains, 9 Gram-negative bacterial strains, and 5 yeast strains ( $\triangleright$ Table 3 ). The results demonstrated stronger antibacterial activity of all extracts against Gram-positive bacteria, and against two pathogenic bacteria, Streptococcus pyogenes and Shigella sonnei (MIC $\leq 0.3 \mathrm{mg} /$ $\mathrm{mL}$ ). The AcOEt extract was the most active against all tested microorganisms. The antimicrobial activity of the isolated compounds was first evaluated with an immersion bioautography method [39] against Staphylococcus aureus CIP 53.154 ( $\triangleright$ Table 4). Five compounds, among them decaffeoylacteoside and verbascoside that showed growth inhibition areas close to the ones observed with the antibiotic controls, as well as luteolin, p-methoxycinnamic acid and 6-O-E-caffeoyl-ajugol, seemed promising antimicrobial candi- dates. Our results were in agreement with the literature on antibacterial activity of verbascoside [40], luteolin [41], and p-methoxycinnamic acid [42].

A serial dilution technique in 96-well plates was used to determine the MIC of the active compounds against five bacteria ( $\triangleright$ Table 4); the best inhibitory activity was found for the two phenylethanoid diglycosidic compounds, decaffeoylacteoside and verbascoside $(\mathrm{MIC}=31 \mu \mathrm{g} / \mathrm{mL})$, and for $\mathrm{p}$-methoxycinnamic acid $(\mathrm{MIC}=62 \mu \mathrm{g} / \mathrm{mL})$.

In summary, it may be concluded from this study that iridoid glucosides could be considered as chemical markers of Bignoniaceae, represented here by sixteen compounds amongst which three were never described before. The 6-O-esterified iridoids like minecoside and 6-O-caffeoyl-ajugol had weaker antibacterial activity than reported for the non-esterified aucubin [43]. Six compounds of the methanol extract of $D$. spathacea showed a strong inhibitory activity against resistant bacterial strains, particularly against 
- Table $2{ }^{1} \mathrm{H}$ - and ${ }^{13} \mathrm{C}$-NMR spectroscopic data $\left(\mathrm{CD}_{3} \mathrm{OD}\right)$ of saponins (4) and (5).

\begin{tabular}{|c|c|c|c|c|}
\hline & \multicolumn{2}{|l|}{ (4) } & \multicolumn{2}{|l|}{ (5) } \\
\hline & $\delta_{\mathrm{H}}(\mathrm{J}$ in $\mathrm{Hz})$ & $\delta_{\mathrm{c}}$ & $\delta_{\mathrm{H}}(\mathrm{J}$ in $\mathrm{Hz})$ & $\delta_{c}$ \\
\hline 1 & $\begin{array}{l}0.98-1.03 \mathrm{~m} \\
1.58-1.66, \mathrm{~m}\end{array}$ & 42.1 & $\begin{array}{l}0.94-1.04, \mathrm{~m} \\
1.58-1.65, \mathrm{~m}\end{array}$ & 41.7 \\
\hline 2 & $\begin{array}{l}1.58-1.66, \mathrm{~m} \\
1.70-1.78, \mathrm{~m} \\
\end{array}$ & 28.0 & $\begin{array}{l}1.58-1.65, \mathrm{~m} \\
1.71-1.79, \mathrm{~m}\end{array}$ & 27.6 \\
\hline 3 & $3.10, \mathrm{dd}(11.7,4.1)$ & 80.2 & $3.58, \mathrm{dd}(11.7,3.8)$ & 73.9 \\
\hline 4 & & 40.7 & & 44.2 \\
\hline 5 & 0.75, brs & 57.2 & 1.19, brs & 49.5 \\
\hline 6 & 4.50, brs $\left(w_{1 / 2}=7.5\right)$ & 69.0 & 4.41, brs $\left(w_{1 / 2}=7.8\right)$ & 68.9 \\
\hline 7 & $\begin{array}{c}1.55, \mathrm{dd}(14.5,2.0) \text { eq } \\
1.70-1.78, \mathrm{~m} \mathrm{ax}\end{array}$ & 41.8 & $\begin{array}{c}1.51, \text { brd }(14.2) \\
1.78-1.85, \mathrm{~m}\end{array}$ & 41.4 \\
\hline 8 & & 40.3 & & 40.3 \\
\hline 9 & 1.70-1.76, m & 49.0 & 1.71-1.79, m & 48.9 \\
\hline 10 & & 37.6 & & 37.3 \\
\hline 11 & $2.00-2.12, \mathrm{~m}$ & 24.7 & $2.01-2.13, \mathrm{~m}$ & 24.7 \\
\hline 12 & $5.36, \mathrm{t}(3.4)$ & 130.0 & 5.36, brt (3.4) & 130.0 \\
\hline 13 & & 138.9 & & 138.9 \\
\hline 14 & & 43.1 & & 43.1 \\
\hline 15 & $\begin{array}{c}\text { 1.91, td }(14.0,4.4) \text { ax } \\
1.03, \mathrm{~m} \text { eq }\end{array}$ & 29.7 & $\begin{array}{c}1.91, \mathrm{td}(13.9,3.9) \mathrm{ax} \\
1.01-1.04, \mathrm{~m} \text { eq }\end{array}$ & 29.7 \\
\hline 16 & $\begin{array}{c}2.62, \mathrm{td}(13.3,4.3) \text { ax } \\
1.64-1.68, \mathrm{~m} \text { eq }\end{array}$ & 26.6 & $\begin{array}{l}\text { 2.62, td }(13.3,4.3) \text { ax } \\
1.66, \text { brd }(13.0) \text { eq }\end{array}$ & 26.6 \\
\hline 17 & & 49.3 & & 48.6 \\
\hline 18 & 2.55 , brs & 55.0 & $2.25, \mathrm{~s}$ & 55.0 \\
\hline 19 & & 73.7 & & 73.7 \\
\hline 20 & 1.34-1.40, m & 43.0 & $1.35-1.40, \mathrm{~m}$ & 43.0 \\
\hline 21 & $\begin{array}{l}1.29-1.24, \mathrm{~m} \\
1.73-1.77, \mathrm{~m}\end{array}$ & 27.2 & $\begin{array}{l}1.24-1.29, \mathrm{~m} \\
1.71-1.79, \mathrm{~m}\end{array}$ & 27.2 \\
\hline 22 & $\begin{array}{l}1.64-1.68, \mathrm{~m} \\
1.78-1.83, \mathrm{~m}\end{array}$ & 38.3 & $\begin{array}{c}1.66, \text { brd }(12.6) \\
1.78-1.85, \mathrm{~m}\end{array}$ & 38.3 \\
\hline 23 & $1.07, \mathrm{~s}$ & 28.4 & $\begin{array}{l}3.50, d(10.9) \\
3.62, d(11.0)\end{array}$ & 66.8 \\
\hline 24 & $1.18, \mathrm{~s}$ & 17.6 & $1.09, \mathrm{~s}$ & 14.1 \\
\hline 25 & $1.33, \mathrm{~s}$ & 17.4 & $1.35, \mathrm{~s}$ & 17.7 \\
\hline 26 & $1.07, \mathrm{~s}$ & 18.7 & $1.07, \mathrm{~s}$ & 18.7 \\
\hline 27 & $1.32, \mathrm{~s}$ & 24.7 & $1.33, \mathrm{~s}$ & 24.7 \\
\hline 28 & & 178.5 & & 178.5 \\
\hline 29 & $1.23, \mathrm{~s}$ & 27.1 & $1.23, \mathrm{~s}$ & 27.1 \\
\hline 30 & $0.95, \mathrm{~d}(6.7)$ & 16.6 & $0.95, \mathrm{~d}(6.7)$ & 16.6 \\
\hline \multicolumn{5}{|c|}{$\beta$-D-glucopyranose (C-28) } \\
\hline $1^{\prime}$ & $5.33, \mathrm{~d}(8.1)$ & 95.9 & $5.33, \mathrm{~d}(8.2)$ & 95.9 \\
\hline $2^{\prime}$ & 3.34, brt (8.2) & 73.9 & $3.35, \mathrm{t}(8.2)$ & 73.9 \\
\hline $3^{\prime}$ & $3.43, \mathrm{t}(8.9)$ & 78.3 & $3.43, \mathrm{t}(8.8)$ & 78.3 \\
\hline $4^{\prime}$ & $3.37, \mathrm{t}(9.0)$ & 71.2 & $3.38, \mathrm{dd}(9.4,8.5)$ & 71.2 \\
\hline $5^{\prime}$ & 3.32-3.36, m & 78.6 & 3.32-3.36, m & 78.6 \\
\hline $6^{\prime}$ & $\begin{array}{l}\text { 3.82, dd }(11.8,2.0) \\
3.70, \mathrm{dd}(11.9,4.6)\end{array}$ & 62.4 & $\begin{array}{l}3.83, \mathrm{dd}(12.0,1.9) \\
3.71, \mathrm{dd}(12.0,4.6)\end{array}$ & 62.4 \\
\hline
\end{tabular}

$P$. aeruginosa and $E$. faecalis. Dicaffeoylacteoside, verbascoside, and p-methoxycinnamic acid, the major compounds of the methanol extract, possessed strong antibacterial activity against most of the strains tested (MIC $<100 \mu \mathrm{g} / \mathrm{mL}$ ). This result may explain the use of this species in folk medicine to treat oral thrush, bronchitis, and eye infection as well as cutaneous antiseptic. The large number and wide diversity of isolated compounds from leaves of $D$. spathacea supported the other traditional uses of this plant in gastrointestinal diseases as depurative, carminative, and against liver disease. 
- Table 3 Minimal inhibitory concentration of extracts from Dolichandrone spathacea.

\begin{tabular}{|c|c|c|c|c|c|c|c|c|c|}
\hline & \multirow[b]{2}{*}{ Microbial strain } & \multicolumn{5}{|c|}{ MIC of extract $(\mathrm{mg} / \mathrm{mL})$} & \multirow[b]{2}{*}{ Vancomycine } & \multirow[b]{2}{*}{ Gentamicine } & \multirow[b]{2}{*}{$\begin{array}{l}\text { Amphop- } \\
\text { tericin B }\end{array}$} \\
\hline & & $\begin{array}{c}\text { Petroleum } \\
\text { ether }\end{array}$ & $\mathrm{CHCl}_{3}$ & AcOEt & $\mathrm{MeOH}$ & $\begin{array}{c}\text { Aqueous } \\
\mathrm{MeOH}\end{array}$ & & & \\
\hline \multirow{8}{*}{ 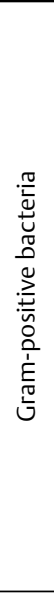 } & Bacillus subtilis ATCC 6633 & 5 & 1.2 & 5 & 10 & 10 & $\mathrm{~s}$ & $\mathrm{~s}$ & NT \\
\hline & $\begin{array}{l}\text { Enterococcus faecalis ATCC } \\
1034\end{array}$ & 5 & 2.5 & 10 & 10 & 10 & $R$ & $R$ & NT \\
\hline & $\begin{array}{l}\text { Staphylococcus aureus CIP } \\
8325-4\end{array}$ & 5 & 2.5 & 5 & NA & 10 & $S$ & $S$ & NT \\
\hline & $\begin{array}{l}\text { Staphylococcus aureus CIP } \\
53.154\end{array}$ & 5 & 2.5 & 5 & 2.5 & 10 & $S$ & $S$ & NT \\
\hline & $\begin{array}{l}\text { Micrococcus luteus (lab. } \\
\text { collection) }\end{array}$ & 5 & 1.2 & 5 & 5 & 10 & $S$ & $S$ & NT \\
\hline & $\begin{array}{l}\text { Listeria innocua (lab. } \\
\text { collection) }\end{array}$ & 5 & 2.5 & 5 & NA & 10 & $S$ & $S$ & NT \\
\hline & $\begin{array}{l}\text { Staphylococcus epidermidis } \\
\text { (lab. collection) }\end{array}$ & $\leq 0.3$ & 1.2 & 2.5 & 10 & 10 & $S$ & $S$ & NT \\
\hline & $\begin{array}{l}\text { Streptococcus pyogenes } \\
\text { (lab. collection) }\end{array}$ & $\leq 0.3$ & $\leq 0.3$ & $\leq 0.3$ & $\leq 0.3$ & $\leq 0.3$ & $S$ & $S$ & NT \\
\hline \multirow{9}{*}{ 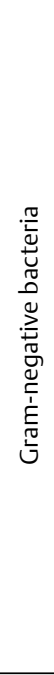 } & $\begin{array}{l}\text { Providencia stuartii (lab. } \\
\text { collection) }\end{array}$ & 5 & 1.2 & 5 & NA & 10 & $R$ & $S$ & NT \\
\hline & $\begin{array}{l}\text { Pseudomonas aeruginosa } \\
\text { ATCC } 9027\end{array}$ & 10 & NA & 10 & 10 & 10 & $\mathrm{R}$ & $S$ & NT \\
\hline & $\begin{array}{l}\text { Shigella sonnei (lab. } \\
\text { collection) }\end{array}$ & $\leq 0.3$ & $\leq 0.3$ & $\leq 0.3$ & $\leq 0.3$ & $\leq 0.3$ & 1 & $S$ & NT \\
\hline & $\begin{array}{l}\text { Proteus vulgaris (lab. } \\
\text { collection) }\end{array}$ & NA & NA & 10 & NA & 10 & $R$ & $S$ & NT \\
\hline & $\begin{array}{l}\text { Klebsiella pneumoniae (lab. } \\
\text { collection) }\end{array}$ & NA & NA & 10 & NA & NA & $\mathrm{R}$ & $R$ & NT \\
\hline & $\begin{array}{l}\text { Serratia marcescens (lab. } \\
\text { collection) }\end{array}$ & NA & NA & 10 & NA & 10 & $\mathrm{R}$ & $S$ & NT \\
\hline & Escherichia coli CIP 54.127 & NA & NA & 10 & NA & NA & $R$ & $S$ & NT \\
\hline & $\begin{array}{l}\text { Enterobacter cloacae (lab. } \\
\text { collection) }\end{array}$ & NA & NA & 10 & NA & NA & $R$ & $S$ & NT \\
\hline & $\begin{array}{l}\text { Salmonella enterica (lab. } \\
\text { collection) }\end{array}$ & NA & NA & 10 & NA & 10 & $R$ & $S$ & NT \\
\hline \multirow{5}{*}{ 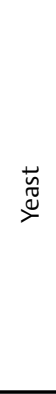 } & $\begin{array}{l}\text { Candida glabrata (lab. } \\
\text { collection) }\end{array}$ & 2.5 & 1.2 & 5 & NA & 10 & $R$ & $\mathrm{R}$ & $S$ \\
\hline & $\begin{array}{l}\text { Candida tropicalis (lab. } \\
\text { collection) }\end{array}$ & 5 & 10 & 5 & NA & 10 & $\mathrm{R}$ & $\mathrm{R}$ & $S$ \\
\hline & $\begin{array}{l}\text { Candida kefyr (lab. } \\
\text { collection) }\end{array}$ & 5 & 10 & 10 & NA & NA & $\mathrm{R}$ & $R$ & $S$ \\
\hline & $\begin{array}{l}\text { Cryptococcus neoformans } \\
\text { (lab. collection) }\end{array}$ & 10 & NA & 10 & NA & NA & $R$ & $R$ & $S$ \\
\hline & $\begin{array}{l}\text { Candida albicans ATCC } \\
2091\end{array}$ & 5 & 10 & 5 & NA & 10 & $R$ & $R$ & $S$ \\
\hline
\end{tabular}

\section{Material and Methods}

\section{General experimental procedures}

Optical rotations were determined with a Perkin-Elmer 341 polarimeter. UV-Vis spectra were measured with a Shimadzu UV/Vis U-2450 spectrophotometer. IR spectra were recorded on a Nicolet Impact 410 FTIR spectrometer. HR-ESI-MS experiments were performed using a Micromass Q-TOF micro instrument. NMR spectra were acquired in $\mathrm{CD}_{3} \mathrm{OD}$ on a Bruker Avance DRX-600 instrument using standard pulse sequences and parameters. TLC was performed on pre-coated silica-gel $60 \mathrm{~A}$ : Alugram UV 254 MachereyNagel in normal phase, and Silicagel 60 RP-18 $F_{254 S}$ Merck in inversed phase. CC and vacuum liquid chromatography (VLC) were realized on Kieselgel 60 (63-200 mesh), Merck. Flash chromatography (FC) was carried out on a Grace Reveleris apparatus equipped with a detector ELSD, a detector UV/vis and Reveleris Flash System software. HPLC was performed on a Dionex apparatus equipped 
- Table 4 Bioautography and Minimal Inhibitory Concentration of antimicrobial compounds of Dolichandrone spathacea.

\begin{tabular}{|c|c|c|c|c|c|c|}
\hline \multirow[b]{2}{*}{ Compound } & \multirow{2}{*}{$\begin{array}{c}\text { Bioautography } \\
\text { S. aureus } \\
\text { CIP } 53.154\end{array}$} & \multicolumn{5}{|c|}{ MIC ( $\mu \mathrm{g} / \mathrm{mL})$} \\
\hline & & $\begin{array}{l}\text { S. aureus } \\
\text { CIP } 53.154\end{array}$ & $\begin{array}{l}\text { E. faecalis } \\
\text { ATCC } 1034\end{array}$ & $\begin{array}{l}\text { S. pyogenes } \\
\text { (lab. collection) }\end{array}$ & $\begin{array}{l}\text { P. aeruginosa } \\
\text { ATCC } 9027\end{array}$ & $\begin{array}{c}\text { S. sonnei } \\
\text { (lab. collection) }\end{array}$ \\
\hline decaffeoylacteoside & +++ & 62.5 & 31.2 & 62.5 & 250 & 31.2 \\
\hline verbascoside & +++ & 125 & 31.2 & 125 & 250 & 31.2 \\
\hline luteolin & ++ & 250 & 250 & 125 & 500 & 125 \\
\hline p-methoxycinnamic acid & ++ & 62.5 & 125 & 62.5 & 125 & 62.5 \\
\hline minecoside & NA & $\mathrm{NA}$ & 500 & 250 & 500 & 250 \\
\hline 6-O-E-caffeoylajugol & ++ & 125 & 250 & 125 & 500 & 125 \\
\hline Vancomycin & +++ & 3.9 & 62.5 & $\leq 1.9$ & 62.5 & 7.8 \\
\hline Gentamicin & +++ & $\leq 1.9$ & 15.6 & 1.9 & 7.8 & $\leq 1.9$ \\
\hline
\end{tabular}

with a LPG 3400AB pump, an ASI-100 auto-sampler, a diode array detector UVD 340 S, an oven STH 585, and a Chromeleon software. Phenomenex Luna C 18 columns $(5 \mu, 100 \AA$; $250 \times 10$ mm: column 1; $250 \times 15 \mathrm{~mm}$ : column 2) and Interchrom Uptisphere Strategy C18 column $(2-5 \mu, 250 \times 10 \mathrm{~mm}$ : column 3$)$ were used for semipreparative HPLC with gradient eluent [solvent $\mathrm{A}, \mathrm{H}_{2} \mathrm{O}$ or $\mathrm{H}_{2} \mathrm{O}(\mathrm{pH}$ $2.4,0.025 \%$ TFA); solvent $\mathrm{B}, \mathrm{MeCN}$ or $\mathrm{MeOH}$ ], and the chromatogram was monitored at 205 and $254 \mathrm{~nm}$. Preparative HPLC chain comprises a Merck column of $200 \times 50 \mathrm{~mm}$ packed with $\mathrm{C}-18$ silica gel, an Armen AP 250/500 pump, an ACC 250/500 injector, and an UV Merck K-2501 Knauer detector; fractions were collected using a Büchi C-660 collector. Sugars were purified on a Waters chromatographic chain with a Rezex ROA column $(250 \times 21.2 \mathrm{~mm}$ : column 4), Empower software, a 600 E pump, a 717 plus auto-sampler, and a refractive index $(\mathrm{RI})$ detector (flow rate $=3.5 \mathrm{~mL} / \mathrm{min}$, pressure $=1400 \mathrm{psi})$; Chiralpak IC column $(5 \mu \mathrm{m}, 250 \times 4.6 \mathrm{~mm}$ : column 5) was used for the chiral identification of sugars (flow rate $=0.5 \mathrm{~mL}$ ) $\min$, pressure $=300 \mathrm{psi}$ ).

\section{Plant material}

The leaves of $D$. spathacea were collected in Vinh Long Province, Vietnam in December 2011. The plant was identified by Professor Nghia Thin Nguyen (Faculty of Biology, University of Sciences Hanoi, Vietnam) and a voucher specimen (CTU-CD001) was deposited at the Department of Biology, Faculty of Pedagogy, Can Tho University, Vietnam.

\section{Extraction and isolation}

Dried and powdered leaves $(150 \mathrm{~g})$ were macerated for $7 \mathrm{~h}$ with petroleum ether $(1.5 \mathrm{~L}$ ) to furnish $0.98 \mathrm{~g}$ of extract (yield $0.65 \%$ ), and treated in the same way successively with $1.5 \mathrm{~L} \mathrm{CHCl}_{3}$ for $20 \mathrm{~h}(5 \mathrm{~g}$; yield $3.4 \%$ ), $1.5 \mathrm{~L}$ EtOAc ( $2 \mathrm{~g}$; yield $1.4 \%), 1.5 \mathrm{~L} \mathrm{MeOH} \mathrm{(} 23 \mathrm{~g}$; yield $15.3 \%$ ), and $1.5 \mathrm{~L}$ of $80 \%$ aqueous $\mathrm{MeOH}$ ( $17 \mathrm{~g}$; yield $12 \%$ ).

The $\mathrm{MeOH}$ extract $(2 \times 10 \mathrm{~g})$ was subjected to silica gel VLC $(7 \times 9.5 \mathrm{~cm})$ using a gradient of solvent $\mathrm{CHCl}_{3}-\mathrm{MeOH}-\mathrm{H}_{2} \mathrm{O}$ (100:0:0 - 0:100:5) to give 20 fractions. The $\mathrm{p}$-methoxycinnamic acid $(480 \mathrm{mg})$ was obtained in VLC-fraction 4 eluted with $\mathrm{CHCl}_{3}-$ $\mathrm{MeOH}(90: 10)$.

VLC-fraction 5 [ $620 \mathrm{mg}$, eluted with $\mathrm{CHCl}_{3}-\mathrm{MeOH}$ (85:15)] was separated by C-18 FC using a gradient of $\mathrm{MeOH}-\mathrm{H}_{2} \mathrm{O}(10: 90-$ 100:0); sub-fraction 5.9 [53 mg, eluted with $\mathrm{MeOH}-\mathrm{H}_{2} \mathrm{O}$ (45:55)] was purified by semi-preparative HPLC (column 2;6 mL/min) using an isocratic solvent of $25 \% \mathrm{MeCN}(\mathrm{pH}=2.4)$ during 30 min to yield (2E,6E)-8-hydroxy-2,6-dimethyl-2,6-octadienoic acid (6.2 mg; $R_{t}=10.66 \mathrm{~min}$ ) and (2E,6Z)-8-hydroxy-2,6-dimethyl-2,6-octadienoic acid ( $\left.3.5 \mathrm{mg} ; R_{t}=11.31 \mathrm{~min}\right)$; sub-fraction $5.11(40 \mathrm{mg}$ ) was purified by the same way using an isocratic solvent of $28 \% \mathrm{MeCN}$ to furnish a mixture of $6 \mathrm{R}$ - and $6 \mathrm{~S}-(2 \mathrm{E})-8$-hydroxy-2,6-dimethyl2-octenoic acids (5.8 mg; $R_{t}=14.62 \mathrm{~min}$ ).

VLC-fraction 6 [2.3g, eluted with $\mathrm{CHCl}_{3}-\mathrm{MeOH}(80: 20)$ ] was chromatographed by silica gel $\mathrm{FC}$ using a gradient of $\mathrm{CHCl}_{3}-\mathrm{MeOH}$ (100:0 - 0:100) to obtain p-hydroxycinnamic acid $(22 \mathrm{mg})$ and 6-(E)-p-methoxycinnamoyl-catalpol (240 mg); sub-fraction 6.3 [31 mg, eluted with $\mathrm{CHCl}_{3}-\mathrm{MeOH}$ (93:7)] was purified by semipreparative HPLC (column $1 ; 3 \mathrm{~mL} / \mathrm{min}$ ) using an isocratic mode of $23 \% \mathrm{MeCN}(\mathrm{pH}=2.4)$ to give vanillic acid ( $\left.1 \mathrm{mg} ; \mathrm{R}_{\mathrm{t}}=7.13 \mathrm{~min}\right)$ and isoferulic acid ( $\left.2.3 \mathrm{mg} ; R_{t}=12.39 \mathrm{~min}\right)$; the purification of sub-fraction 6.5 [28 mg, eluted with $\mathrm{CHCl}_{3}-\mathrm{MeOH}$ (91:9)] by semi-preparative HPLC (column 2; $6 \mathrm{~mL} / \mathrm{min}$ ) using a gradient solvent of $20-45 \%$ $\operatorname{MeCN}\left(\mathrm{pH}=2.4\right.$ ) gave $\mathrm{p}$-hydroxybenzoic acid ( $3 \mathrm{mg} ; \mathrm{R}_{\mathrm{t}}=8.69 \mathrm{~min}$ ) and luteolin ( $\left.4.5 \mathrm{mg} ; \mathrm{R}_{\mathrm{t}}=16.18 \mathrm{~min}\right)$; sub-fraction $6.7(470 \mathrm{mg})$ eluted with $\mathrm{CHCl}_{3}-\mathrm{MeOH}$ (90:10) was separated by C-18 FC using a gradient solvent of $\mathrm{MeOH}-\mathrm{H}_{2} \mathrm{O}(10: 90$ - 100:0), then fractions eluted with $\mathrm{MeOH}-\mathrm{H}_{2} \mathrm{O}(60: 40)$ were subjected to silica gel CC using a gradient system of $\mathrm{CHCl}_{3}-\mathrm{MeOH}(100: 0-0: 100)$ to obtain 6-O-(p-methoxy-E-cinnamoyl)-ajugol (1) (50 mg) eluted with $5 \% \mathrm{MeOH}$ and a mixture of (E)- and (Z)-6-p-methoxycinnamoylcatalpol ( $2 \mathrm{mg} ; \mathrm{R}_{\mathrm{t}}=25.46 \mathrm{~min}$ ), finally purified by semi-preparative $\mathrm{HPLC}$ (column 1, $4 \mathrm{~mL} / \mathrm{min}$ ) using an isocratic mode of $28 \% \mathrm{MeCN}$.

VLC-fraction 7 [2.6g, eluted with $\mathrm{CHCl}_{3}-\mathrm{MeOH}$ (75:25)] was chromatographed by preparative $\mathrm{HPLC}$ using a gradient of $\mathrm{MeOH}$ $-\mathrm{H}_{2} \mathrm{O}$ (25:75 - 100:0); sub-fraction 7.5 [32 mg, eluted with $\mathrm{MeOH}$ $-\mathrm{H}_{2} \mathrm{O}$ (35:65)] was separated by semi-preparative HPLC (column $3,4 \mathrm{~mL} / \mathrm{min}$ ) using an isocratic of $28 \% \mathrm{MeCN}(\mathrm{pH}=2.4)$ to obtain a mixture $\left(R_{t}=10.43 \mathrm{~min}\right)$ which was purified by a semi-preparative HPLC using an isocratic of $17 \% \mathrm{MeOH}$ during 55 min to yield $6 \mathrm{~S}, 9 \mathrm{~S}$ roseoside ( $6 \mathrm{mg} ; \mathrm{R}_{\mathrm{t}}=46.98 \mathrm{~min}$ ); the purification of sub-fraction 7.9 [ $90 \mathrm{mg}$, eluted with $\mathrm{MeOH}-\mathrm{H}_{2} \mathrm{O}$ (35:65)] by semi-preparative HPLC (column $3 ; 4 \mathrm{~mL} / \mathrm{min}$ ) using an isocratic mode of $23 \% \mathrm{MeCN}$ gave minecoside ( $5 \mathrm{mg} ; \mathrm{R}_{\mathrm{t}}=14.49 \mathrm{~min}$ ) and 6-O-E-isoferuloyl-ajugol ( $4 \mathrm{mg}$; Rt = 16.15 min); in the same way, sub-fraction 7.10 [87 mg, eluted with $\mathrm{MeOH}-\mathrm{H}_{2} \mathrm{O}$ (35:65)] yielded nemorososide (4 mg; 
$R_{t}=14.70 \mathrm{~min}$ ) and 6" (Z)-nemoroside (7.5 mg; $\left.R t=19.02 \mathrm{~min}\right)$; the 6-O-p-E-coumaroyl-ajugol ( $23 \mathrm{mg} ; \mathrm{R}_{\mathrm{t}}=25.19 \mathrm{~min}$ ) was obtained from sub-fraction 7.12 [50 mg, eluted with $\mathrm{MeOH}-\mathrm{H}_{2} \mathrm{O}(40: 60)$ ] by a semi-preparative HPLC (column $1 ; 4 \mathrm{~mL} / \mathrm{min}$ ) using an isocratic of $20 \% \mathrm{MeCN}$; semi-preparative HPLC (column 3; $3.5 \mathrm{~mL} / \mathrm{min}$ ) of sub-fraction 7.15 [62 mg, eluted with $\mathrm{MeOH}-\mathrm{H}_{2} \mathrm{O}(60: 40)$ ] using an isocratic of $25 \%$ MeCN furnished mixture of 6"'R-(2E) -8-hydroxy-2,6-dimethyl-2-octenoyl)-ajugol (2) (7.5 mg; $R_{\mathrm{t}}=22.54 \mathrm{~min}$ ) and mixture of 6"'R-(2E)-8-hydroxy-2,6-dimethyl-2-octenoyl)-catalpol (3; $\left.10 \mathrm{mg} ; \mathrm{R}_{\mathrm{t}}=25.91 \mathrm{~min}\right)$; in the same way, sub-fraction 7.17 (52 mg, eluted with $\mathrm{MeOH}-\mathrm{H}_{2} \mathrm{O}(65: 35)$ ) gave 6-O-(E) -cinnamoylcatalpol (14 mg; $R_{t}=20.72 \mathrm{~min}$ ); the 28-O- $\beta$-D-glucopyranosyl uncaric acid $\left(4 ; 7.3 \mathrm{mg} ; R_{\mathrm{f}}=0.28\right)$ was obtained from sub-fraction 7.21 (27 mg, eluted with $\mathrm{MeOH}-\mathrm{H}_{2} \mathrm{O}(100: 0)$ ) by using C-18 preparative TLC eluted with $\mathrm{MeOH}-\mathrm{H}_{2} \mathrm{O}(70: 30)$.

VLC-fraction 8 [2.2 g, eluted with $\mathrm{CHCl}_{3}-\mathrm{MeOH}$ (70:30)] was separated by preparative HPLC using a gradient mode of $\mathrm{MeOH}$ $\mathrm{H}_{2} \mathrm{O}(25: 75-100: 0)$ to yield verbascoside [397 $\mathrm{mg}$, eluted with $\mathrm{MeOH}-\mathrm{H}_{2} \mathrm{O}$ (25:75)]; the purification of sub-fraction 8.4 [397 mg, eluted with $\mathrm{MeOH}-\mathrm{H}_{2} \mathrm{O}$ (35:65)] by semi-preparative HPLC (column $3 ; 4 \mathrm{~mL} / \mathrm{min}$ ) using an isocratic of $10 \% \mathrm{MeCN}$ gave decaffeoylacteoside ( $8 \mathrm{mg} ; \mathrm{R}_{\mathrm{t}}=8.61 \mathrm{~min}$ ); semi-preparative HPLC (column 1; $4 \mathrm{~mL} / \mathrm{min}$ ) applied to sub-fraction 8.12 [33 mg, eluted with $\mathrm{MeOH}$ $-\mathrm{H}_{2} \mathrm{O}(40: 60)$ ] was carried out by using an isocratic mode of $20 \%$ MeCN to give verminoside ( $7 \mathrm{mg} ; R_{\mathrm{t}}=11.33 \mathrm{~min}$ ); semi-preparative HPLC (column 3, $3.5 \mathrm{~mL} / \mathrm{min}$ ) of sub-fraction 8.14 [40 mg, eluted with $\mathrm{MeOH}-\mathrm{H}_{2} \mathrm{O}$ (45:55)] yield isoverbascoside (14 mg; $\mathrm{R}_{\mathrm{t}}=18.41 \mathrm{~min}$ ) by using an isocratic mode of $19 \% \mathrm{MeCN}$; sub-fraction 8.15 [12 mg, eluted with $\mathrm{MeOH}-\mathrm{H}_{2} \mathrm{O}$ (45:55)] was purified by semi-preparative HPLC (column 3; $4 \mathrm{~mL} / \mathrm{min}$ ) using an isocratic mode of $18 \%$ MeCN to furnish luteolin-7-O- $\beta$-D-glucopyranoside (7.5 mg; $\left.R_{t}=15.81 \mathrm{~min}\right)$; 6-O-E-caffeoyl-ajugol (7 mg; $R_{t}=24 \mathrm{~min}$ ) was obtained from sub-fraction 8.16 [40 mg, eluted with $\mathrm{MeOH}-$ $\mathrm{H}_{2} \mathrm{O}$ (50:50)] by semi-preparative HPLC (column $1 ; 4 \mathrm{~mL} / \mathrm{min}$ ) using an isocratic mode of $18 \% \mathrm{MeCN}$; the same protocol applied to subfraction 8.18 [33 mg, eluted with $\mathrm{MeOH}-\mathrm{H}_{2} \mathrm{O}$ (55:45)] gave specioside ( $9 \mathrm{mg} ; \mathrm{R}_{\mathrm{t}}=12.87 \mathrm{~min}$ ) using an isocratic mode of $23 \% \mathrm{MeCN}$; the purification of sub-fraction 8.21 [90 mg, eluted with $\mathrm{MeOH}-$ $\left.\mathrm{H}_{2} \mathrm{O}(65: 35)\right]$ yielded arjunglucoside I $\left(6 \mathrm{mg} ; \mathrm{R}_{\mathrm{t}}=13.13 \mathrm{~min}\right)$ and nemoroside ( $9.5 \mathrm{mg} ; \mathrm{R}_{\mathrm{t}}=17.16 \mathrm{~min}$ ) by semi-preparative HPLC (column $3 ; 4 \mathrm{~mL} / \mathrm{min}$ ) using an isocratic mode of $25 \% \mathrm{MeCN}$; sub-fraction 8.23 [20 mg, eluted with $\mathrm{MeOH}-\mathrm{H}_{2} \mathrm{O}(65: 35)$ ] was purified by silica gel preparative TLC eluted with $\mathrm{CHCl}_{3}-\mathrm{MeOH}-\mathrm{H}_{2} \mathrm{O}(80: 20 / 2)$ to yield 28-O- $\beta$-D-glucopyranosyl-23-hydroxy-uncaric acid (5; $\left.7.5 \mathrm{mg} ; \mathrm{R}_{\mathrm{f}}=0.33\right)$.

VLC-fraction $13\left[617 \mathrm{mg}\right.$, eluted with $\mathrm{CHCl}_{3}-\mathrm{MeOH}-\mathrm{H}_{2} \mathrm{O}$ (70:30:5)] was separated by $\mathrm{C}-18 \mathrm{FC}$ using a gradient of $\mathrm{MeOH}-$ $\mathrm{H}_{2} \mathrm{O}(10: 90$ - 100:0) to give 17 sub-fractions; luteolin-7-O-rutinoside ( $6 \mathrm{mg} ; R_{t}=14.85 \mathrm{~min}$ ) was obtained by semi-preparative HPLC (column $1 ; 3.5 \mathrm{~mL} / \mathrm{min}$ ) of sub-fraction 13.9 [18 mg, eluted with $\left.\mathrm{MeOH}-\mathrm{H}_{2} \mathrm{O}(45: 55)\right]$ using an isocratic solvent of $18 \% \mathrm{MeCN}$ $(\mathrm{pH}=2.4)$.

Purification of VLC-fraction 17 [90 mg, eluted with $\mathrm{CHCl}_{3}-$ $\mathrm{MeOH}-\mathrm{H}_{2} \mathrm{O}$ (30:70:5)] by semi-preparative HPLC (column 1; $4 \mathrm{~mL}$ / min) using a gradient mode of $10-35 \% \mathrm{MeCN}(\mathrm{pH}=2.4)$ furnished ixoside (6 mg; $R_{t}=5.79 \mathrm{~min}$ ) and luteolin-7-O-glucuronide $(4.5 \mathrm{mg}$; $R_{t}=15.89$ min).
The purities of all isolated compounds were $\geq 95 \%$, as determined by HPLC and ${ }^{1} \mathrm{H}$ NMR.

Compound 1: amorphous powder; $[\alpha]_{\mathrm{D}}-143$ (c 0.39, MeOH); UV (MeOH) $\lambda_{\max } n m$ (log ع) 202 (2.88), 226 (2.82), 308 (3.09); IR $(\mathrm{KBr}) \mathrm{v}_{\max } \mathrm{Cm}^{-1}: 3428,2931,1706,1662,1632,1575,1514,1170$, 1002, 825; ${ }^{1} \mathrm{H}$ - and ${ }^{13} \mathrm{C}-\mathrm{NMR}$ : see - Table 1; HR-ESI-MS m/z $531.1848[\mathrm{M}+\mathrm{Na}]^{+}$(calcd. for $\left.\mathrm{C}_{25} \mathrm{H}_{32} \mathrm{O}_{11} \mathrm{Na} 531.1842\right), 483.2442$

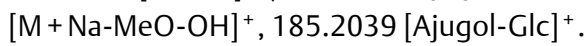

Compound 2: amorphous powder; $[\alpha]_{D}-94$ (c 0.25, MeOH); UV $(\mathrm{MeOH}) \lambda_{\max } \mathrm{nm}(\log \varepsilon) 224$ (3.34), 308 (2.33); ${ }^{1} \mathrm{H}$ - and ${ }^{13} \mathrm{C}-\mathrm{NMR}$ : see Table 1; HR-ESI-MS m/z 539.2462 [M + Na] ${ }^{+}$(calcd. for $\mathrm{C}_{25} \mathrm{H}_{40} \mathrm{O}_{11} \mathrm{Na}$ 539.2468).

Compound 3: amorphous powder; $[\alpha]_{D}-107$ (c 0.22, MeOH); UV (MeOH) $\lambda_{\max } \mathrm{nm}(\log \varepsilon) 224$ (3.33), 308 (2.33); ${ }^{1} \mathrm{H}$ - and ${ }^{13} \mathrm{C}-$ NMR: see - Table 1; HR-ESI-MS m/z 553.2256 [M + Na $]^{+}$(calcd. for

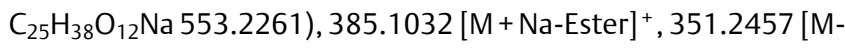
$\mathrm{Glc}]^{+}$.

Compound 4: white powder; $[\alpha]_{D}-18$ (c 0.12, MeOH); UV $(\mathrm{MeOH}) \lambda_{\max } \mathrm{nm}(\log \varepsilon) 210$ (3.37), 308 (3.05); IR (KBr) $\mathrm{v}_{\max } \mathrm{cm}^{-1}$ : 3423, 2929, 1734, 1653, 1458, 1383, 1074; ${ }^{1} \mathrm{H}$ - and ${ }^{13} \mathrm{C}-N M R$ : see - Table 2; HR-ESI-MS m/z 673.3934 [M + Na] ${ }^{+}$(calcd. for $\mathrm{C}_{36} \mathrm{H}_{58} \mathrm{O}$ $\left.{ }_{10} \mathrm{Na} 673.3928\right), 457.2697$ [M-Glc-OH] ${ }^{+}$.

Compound 5: white powder; $[\alpha]_{\mathrm{D}}-7$ (c 0.19, $\left.\mathrm{MeOH}\right) ; \mathrm{UV}(\mathrm{MeOH})$ $\lambda_{\max } \mathrm{nm}(\log \varepsilon) 214$ (3.43), 298 (2.83); IR (KBr) $\mathrm{v}_{\max } \mathrm{Cm}^{-1}: 3422$, 2927, 1732, 1598, 1455, 1384, 1072; ${ }^{1} \mathrm{H}$ - and ${ }^{13} \mathrm{C}-N M R$ : see $>$ Table 2; HR-ESI-MS m/z 689.3869 [M + Na ] ${ }^{+}$(calcd. for $\mathrm{C}_{36} \mathrm{H}_{58} \mathrm{O}_{11} \mathrm{Na}$ 689.3877), $503.3242[\mathrm{M}-\mathrm{Glc}]^{+}$.

\section{Acid hydrolysis}

The MeOH extract $(1 \mathrm{~g})$ was refluxed in $25 \mathrm{~mL}$ of $2 \mathrm{~N} \mathrm{HCl}$ in $4 \mathrm{~h}$. After extraction with EtOAc $(3 \times 25 \mathrm{~mL})$, the aqueous layer was neutralized with $0.5 \mathrm{M} \mathrm{NaOH}$ and freeze-dried. The glucose was identified by comparison with an authentic sample by TLC using MeCOEt - i$\mathrm{PrOH}-\mathrm{MeCOMe}-\mathrm{H}_{2} \mathrm{O}(20 / 10 / 7 / 6)$. It was purified by semi-preparative HPLC (column 4) using $2.5 \mu \mathrm{M} \mathrm{H}_{2} \mathrm{SO}_{4}$ as solvent, and identified by chiral analytic HPLC (column 5 ) using an isocratic mixture of $n$-hexane/EtOH/TFA (80/20/1) in comparison with the authentic samples of $D$-glucose $\left(R_{t}=19.44 \mathrm{~min}\right)$ and $L$-glucose $\left(R_{t}=18.73 \mathrm{~min}\right)$.

\section{Alkaline hydrolysis}

$4 \mathrm{mg}$ of $(\mathbf{2}$ or $\mathbf{3}$ ) were dissolved in $1 \mathrm{~mL}$ of $2 \mathrm{~N} \mathrm{NaOH}$ and stirred overnight. The solution was treated with $\mathrm{Et}_{2} \mathrm{O}(3 \times 1 \mathrm{~mL})$ to remove neutral material. Acidification with dilute $\mathrm{HCl}$ was followed by extraction with $\mathrm{Et}_{2} \mathrm{O}(3 \times 1 \mathrm{~mL})$. The $\mathrm{Et}_{2} \mathrm{O}$ extract were evaporated in vacuo and residue was purified by semi-preparative HPLC to give $1.2 \mathrm{mg}$ (or $1.5 \mathrm{mg}$ ) of monoterpenic acid.

\section{Antimicrobial assays}

After an overnight culture at $37^{\circ} \mathrm{C}$ in Mueller-Hinton (MH) medium, the bacteria (ATCC or CIP collections or clinical strains) and yeasts (clinical strains) were resuspended in fresh $\mathrm{MH}$ medium up to the working solution of 105 microorganisms $/ \mathrm{mL}$. The clinical strains were part of the internal laboratory of microbiology or parasitology collections. All the antibiotics were used in serial dilutions with the higher working concentration of $64 \mathrm{mg} / \mathrm{L}$. 
To determine the minimum inhibitory concentration (MIC) of the extracts, agar plates containing six different concentrations $(10,5,2.5,1.2,0.6$, and $0.3 \mathrm{mg} / \mathrm{mL})$ of each extract were loaded with the different microorganism using a multiple inoculator (Steers). After $24 \mathrm{~h}$ of incubation at $37^{\circ} \mathrm{C}$, the activity was estimated looking at the presence or absence of colonies. Solvents used to prepare extracts and $\mathrm{MH}$ agar medium were checked for absence of antibacterial activity (negative controls). Positive active controls were gentamicin ( $\geq 99 \%$ of purity) and vancomycin ( $\geq 99 \%$ of purity) for antibacterial assays, and amphotericin B ( $\geq 99 \%$ of purity) for anti-yeast assays.

The immersion bioautography method was used to identify the active compounds against S. aureus CIP 53.154. $10 \mu \mathrm{L}$ of each compound $(2 \mathrm{mg} / \mathrm{mL}$ of methanol) or gentamicin $(50 \mu \mathrm{g} / \mathrm{mL}$, positive control) were spotted onto TLC plates $(10 \times 10 \mathrm{~cm})$. The plates were than dried, sterilized and covered by the $\mathrm{MH}$ agar medium containing S. aureus $\left(10^{5}\right.$ bacteria $/ \mathrm{mL}$ ) in square Petri dishes. After incubation for $24 \mathrm{~h}$ at $37^{\circ} \mathrm{C}$, bacterial growth was revealed by a $2 \mathrm{mg} / \mathrm{mL}$ solution of thiazolylbluetetrazolium bromide (MTT) and growth inhibition zones were measured [39].

The broth microdilution method in 96 -well plates was used to determine MIC of active compounds against five bacteria sensitive to the extracts. Nine concentrations of each compound, from $500 \mu \mathrm{g} / \mathrm{mL}$ to $1.9 \mu \mathrm{g} / \mathrm{mL}$ in a serially twofold dilution, were tested against $0.5 \times 10^{5}$ bacteria $/ \mathrm{mL}$, in a total volume of $200 \mu \mathrm{L}$, and incubated overnight at $37^{\circ} \mathrm{C}$. Positive control wells with bacteria in $\mathrm{MH}$ medium, gentamicin or vancomycin, as well as negative controls such as medium alone or medium with methanol were systematically added to the test. Bacterial growth was followed visually and by spraying MTT incubating at $37^{\circ} \mathrm{C}$ for at least $10 \mathrm{~min}$. The MIC value was determined as the lowest concentration of a compound leading to a clear well. This test was performed in triplicate.

\section{Supporting information}

Tables with ${ }^{1} \mathrm{H}$ - and ${ }^{13} \mathrm{C}$-NMR data of the 30 known compounds, and ${ }^{1} \mathrm{H}$ - and ${ }^{13} \mathrm{C}$-NMR Spectra of compounds (1-5) are available as Supporting Information.

\section{Acknowledgments}

The authors wish to thank Dominique Harakat (ICMR) for recording mass spectra, Prof. Nghia Thin Nguyen for the plant identification, Dien Trung Nguyen and Hoang Viet Ho (Can Tho University) for the plant collection, Dr. Georges Massiot (ICMR) for stimulating discussions, Prof. Christophe De Champs and Janick Madoux (Laboratory of Bacteriology, CHU Reims) for access to multiple inoculators material, and Prof. Jerome Depaquit (Laboratory of parasitology-mycology, University of Reims) for providing yeasts.

\section{Conflict of Interest}

The authors declare no conflict of interest.
References

[1] Wiart C. Medicinal plants of the Asia-pacific: drugs for future? Singapore: World Scientific Publishing; 2006: 565-566

[2] Kaewpiboon C, Lirdprapamongkol K, Srisomsap C, Winayanuwattikun P, Yongvanich T, Puwaprisirisan P, Svasti J, Assavalapsakul W. Studies of the in vitro cytotoxic, antioxidant, lipase inhibitory and antimicrobial activities of selected Thai medicinal plants. BMC Complement Altern Med 2012; 12: 217-224

[3] Prasad PRC, C. Reddy S, Raza SH, Dutt CBS. Folklore medicinal plants of North Andaman Island, India. Fitoterapia 2008; 79: 458-464

[4] Jong-Anurakkun N, Bhandari MR, Kawabata J. $\alpha$-Glucosidase inhibitors from Devil tree (Alstonia scholaris). Food Chem 2007; 103: 1319-1323

[5] Saiful A], Mastura M, Mazurah MI, Nuziah H. Inhibitory potential against methicillin-resistant Staphylococcus aureus (MRSA) of Dolichandrone spathacea, a mangrove tree species of Malaysia. Lat Am J Pharm 2011; 30: 359-362

[6] Nishimura H, Sasaki H, Morota T, Chin M, Mitsuhashi H. Six iridoid glycosides from Rehmannia glutinosa. Phytochemistry 1989; 28: 2705-2709

[7] Harinantenaina L, Kasai R, Rakotovao M, Yamasali K. New iridoid and phenethyl glycosides from Malagasy medicinal plant, Phyllarthron madagascariense. J Nat Med 2001; 55: 187-192

[8] Junior P. Nemoroside and Nemorososide, zwei neue Iridoidglucoside aus Penstemon nemorosus. Planta Med 1983; 47: 67-70

[9] Sarg T, Salama O, El-Domiaty M, Bishr M, Mansour ES, Weight E. Iridoid glucosides from Gentiana kurroo Royle. Alex J Pharm Sci 1991; 5 : 82-86

[10] El-Naggar SF, Doskotch RW. Specioside: a new iridoid glycoside from Catalpa speciosa. J Nat Prod 1980; 43: 524-526

[11] Houghton PJ, Hikino H. Anti-hepatotoxic activity of extracts and constituents of Buddleja species. Planta Med 1989; 55: 123-126

[12] Dellar JE, Conn BJ, Cole MD, Waterman PG. Cinnamate esters of catalpol from Westringia fruticosa and Westringia viminalis. Biochem Syst Ecol 1996; 24: 65-69

[13] Sticher O, Afifi-Yazar FU. Minecosid und Verminosid, zwei neue Iridoidglucoside aus Veronica officinalis L. (Scrophulariaceae). Helv Chim Acta 1979; 62: 535-539

[14] Arslanian RL, Anderson T, Stermitz FR. Iridoid glucosides of Penstemon ambiguus. J Nat Prod 1990; 53: 1485-1489

[15] Takeda Y, Nishimura H, Inouye H. Two new iridoid glucosides from Ixora chinensis. Phytochemistry 1975; 14: 2647-2650

[16] Abe F, Yamauchi T. Glycosides of 19 $\alpha$-hydroxyoleanane-type triterpenoids from Trachelospermum asiaticum (Trachelospermum. IV). Chem Pharm Bull 1987; 35: 1833-1838

[17] Karasawa H, Kobayashi H, Takizawa N, Miyase T, Fukushima S. Studies on the constituents of Cistanchis Herba. VII: Isolation and structures of Cistanosides H and I. Yakugaku Zasshi 1986; 106: 562-566

[18] Andary C, Wylde R, Laffite C, Privat G, Winternitz F. Structures of verbascoside and orobanchoside, caffeic acid sugar esters from Orobanche rapum-genistae. Phytochemistry 1982; 21: 1123-1127

[19] Suo M, Ohta T, Takano F, Jin S. Bioactive phenylpropanoid glycosides from Tabebuia avellanedae. Molecules 2013; 18: 7336-7345

[20] Liu QM, Zhao HY, Zhong XK, Jiang JG. Eclipta prostrata L. phytochemicals: Isolation, structure elucidation, and their antitumor activity. Food Chem Toxicol 2012; 50: 4016-4022

[21] Orhan F, Barış O, Yanmış D, Bal T, Güvenalp Z, Güllüce M. Isolation of some luteolin derivatives from Mentha longifolia (L.) Hudson subsp. longifolia and determination of their genotoxic potencies. Food Chem 2012; 135: 764-769 
[22] Özgen U, Mavi A, Terzi Z, Kazaz C, Asçi A, Kaya Y, Seçen H. Relationship between chemical structure and antioxidant activity of luteolin and its glycosides isolated from Thymus sipyleus subsp. sipyleus var. sipyleus. Rec Nat Prod 2011; 5: 12-21

[23] Kokotkiewicz A, Luczkiewicz M, Sowinski P, Glod D, Gorynski K, Bucinski A. Isolation and structure elucidation of phenolic compounds from Cyclopia subternata Vogel (honeybush) intact plant and in vitro cultures. Food Chem 2012; 133: 1373-1382

[24] Iwagawa T, Asai H, Hase T, Sako S, Su R, Hagiwara N, Kim M. Monoterpenoids from Radermachia sinica. Phytochemistry 1990; 29 : 1913-1916

[25] Ono T, Koutari S, Marumoto S, Miyazawa M. Novel compound, (2Z,6E)-1-hydroxy-3,7-dimethyl-2,6-octadien-8-oic acid produced from biotransformation of nerol by Spodoptera litura Larvae. J Oleo Science 2013; 62: 313-318

[26] Yamaguchi K, Shinohara C, Kojima S, Sodeoka M, Tsuji T. (2E,6 R)8-Hydroxy-2,6-dimethyl-2-octenoic acid, a novel anti-osteoporotic monoterpene, isolated from Cistanche salsa. Biosci Biotechnol Biochem 1999; 63: 731-735

[27] Machida K, Ando M, Yaoita Y, Kakuda R, Kikuchi M. Studies on the constituents of Catalpa species. VI. Monoterpene glycosides from the fallen leaves of Catalpa ovata G. Don. Chem Pharm Bull 2001; 49: 732-736

[28] Peungvicha P, Temsiririrkkul R, Prasain JK, Tezuka Y, Kadota S, Thirawarapan SS, Watanabe H. 4-Hydroxybenzoic acid: a hypoglycemic constituent of aqueous extract of Pandanus odorus root. J Ethnopharmacol 1998; 62: 79-84

[29] Sakushima A, Coşkun M, Maoka T. Hydroxybenzoic acids from Boreava orientalis. Phytochemistry 1995; 40: 257-261

[30] Silva AMS, Alkorta I, Elguero ], Silva VLM. A 13C NMR study of the structure of four cinnamic acids and their methyl esters. J Mol Struct 2001; 595: 1-6

[31] Kelley C], Harruff RC, Carmack M. Polyphenolic acids of Lithospermum ruderale. II. Carbon-13 nuclear magnetic resonance of lithospermic and rosmarinic acids. J Org Chem 1976; 41: 449-455

[32] Çalış I, Kuruüzüm-Uz A, Lorenzetto PA, Rüedi P. (6S)-Hydroxy-3-oxo- $\alpha$ ionol glucosides from Capparis spinosa fruits. Phytochemistry 2002; 59: 451-457
[33] Yamano Y, Ito M. Synthesis of optically active vomifoliol and roseoside stereoisomers. Chem Pharm Bull 2005; 53: 541-546

[34] Couperus PA, Clague ADH, van Dongen JPCM. 13 C chemical shifts of some model olefins. Org Magn Reson 1976; 8: 426-431

[35] Dinda B, Debnath S, Harigaya Y. Naturally occurring iridoids. A review, Part 1. Chem Pharm Bull 2007; 55: 159-222

[36] Acebey-Castellon IL, Voutquenne-Nazabadioko L, Doan TMH, Roseau N, Bouthagane N, Muhammad D, Le Magrex Debar E, Gangloff SC, Litaudon M, Sévenet T, Nguyen VH, Lavaud C. Triterpenoid saponins from Symplocos lancifolia. J Nat Prod 2011; 74: 163-168

[37] Aquino R, De Simone F, Vincieri FF, Pizza C, Gacs-Baitz E. New polyhydroxylated triterpenes from Uncaria tomentosa. J Nat Prod 1990; 53: 559-564

[38] Ma X, Yang C, Zhang Y. Complete assignments of $1 \mathrm{H}$ and $13 \mathrm{C} \mathrm{NMR}$ spectral data for three polyhydroxylated 12-ursen-type triterpenoids from Dischidia esquirolii. Magn Reson Chem 2008; 46: 571-575

[39] Abedini A, Roumy V, Mahieux S, Biabiany M, Standaert-Vitse A, Rivière C, Sahpaz S, Bailleul F, Neut C, Hennebelle T. Rosmarinic acid and its methyl ester as antimicrobial components of the hydroxymethanolic axtract of Hyptis atrorubens Poit. (Lamiaceae). Evid Based Complement Alternat Med 2013; 2013: 604536

[40] Nazemiyeh H, Rahman MM, Gibbons S, Nahar L, Gharamani MA, Talebpour AH, Sarker SD. Assessment of the antibacterial activity of phenylethanoid glycosides from Phlomis lanceolata against multipledrug-resistant strains of Staphylococcus aureus. J Nat Med 2008; 62: 91-95

[41] Joung DK, Lee YS, Han SH, Lee SW, Cha SW, Mun SH, Kong R, Kang $\mathrm{OH}$, Song $\mathrm{HJ}$, Shin DW, Kwon DY. Potentiating activity of luteolin on membrane permeabilizing agent and ATPase inhibitor against methicillin-resistant Staphylococcus aureus. Asian Pac J Trop Med 2016; 9: $19-22$

[42] Rigano D, Formisano C, Basile A, Lavitola A, Senatore F, Rosselli S, Bruno M. Antibacterial activity of flavonoids and phenylpropanoids from Marrubium globosum ssp. libanoticum. Phytother Res 2007; 21: 395-397

[43] Yuan CS, Zhang Q, Xie W, Yang XP, Jia ZJ. Iridoids from Pedicularis kansuensis forma albiflora. Pharmazie 2003; 58: 428-430 